\title{
A Proposal for Developing the Performance of Intermediate Second-Grade Students in Science Tests in Trends in International Mathematics \& Science Study (TIMSS)
}

\author{
Asma Abdulrahman Alshaikh \\ Associate Professor, Department of Curricula and Methods of Educational Science, College of Education, Prince Sattam bin Abdulaziz University, Al- \\ Kharj, Saudi Arabia.
}

Email:dr.asmal@hotmail.com

\begin{abstract}
This study aimed at identifying the reasons responsible for the low performance of the students of the second intermediate grade in science's tests in the Trends in International Mathematics and Science Study (TIMSS). It also intends to provide a proposal for developing the performance of the students of the second intermediate grade in science tests in TIMSS. The study adopts the descriptive methodology. To achieve the results of the study, a questionnaire was prepared to identify the reasons responsible for the low performance of the students of the second intermediate grade in science tests in TIMSS. It consisted of three-dimension i.e. course content, student, and teacher \& teaching performance. The results of the study showed that the study sample members are agreed with a high degree of all items of the questionnaire. Considering these results, the study provided a proposal to develop the performance of the students of the second intermediate grade in science tests in TIMSS. The proposal also consists of the same dimensions i.e. course content, student and teacher \& teaching performance. The study recommends benefiting from the proposal to develop the performance of students of the second intermediate grade in science tests in TIMSS. It also suggests conducting future studies aimed at comparing some variables related to science education and learning in advanced-performing countries and the Kingdom of Saudi Arabia.
\end{abstract}

Keywords: Trends in international mathematics \& Science Study (TIMSS), Performance, Second intermediate grade.

Citation | Asma Abdulrahman Alshaikh (2021). A Proposal for Developing the Performance of Intermediate Second-Grade Students in Science Tests in Trends in International Mathematics \& Science Study (TIMSS). Journal of Education and e-Learning Research, 8(1): 26-33.

History:

Received: 25 September 2020

Revised: 19 October 2020

Accepted: 16 December 2020

Published: 30 December 2020

Licensed: This work is licensed under a Creative Commons

Attribution 3.0 License (cc))

Publisher: Asian Online Journal Publishing Group
Funding: This study received no specific financial support.

Competing Interests: The author declares that there are no conflicts of interests regarding the publication of this paper.

Transparency: The author confirms that the manuscript is an honest, accurate, and transparent account of the study was reported; that no vital features of the study have been omitted; and that any discrepancies from the study as planned have been explained.

Ethical: This study follows all ethical practices during writing.

\section{Contents}

1. Introduction ..........................27

3. Data Analyses

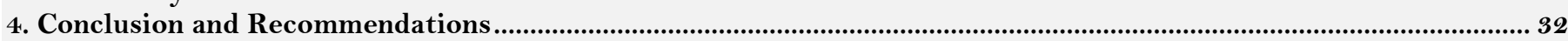

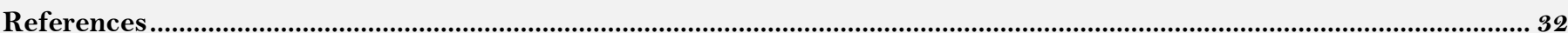




\section{Contribution of this paper to the literature}

This study contributes to the existing literature by identifying the reasons responsible for the low performance of the students of the second intermediate grade in science's tests in the Trends in International Mathematics and Science Study (TIMSS).

\section{Introduction}

All developed countries seek to develop their educational systems to cope up with the rapid changes, accumulation of scientific knowledge, and developments in all areas of life. Hence, it has become imperative for educational institutions to evaluate all their educational systems to achieve their best outcomes. To prepare the generations who are capable to compete in the world, we should prepare them by providing them with knowledge, experience, practical skills, and various thinking skills. In this context, it has become crucial to pay great attention to science and teaching. It is because of the vital role that it plays in achieving the goals of society, and its prosperity in various scientific and technical fields. It provides students with experience which gives them required scientific skills, scientific culture, and life skills (Alhisan, 2015). Many educational institutions have worked on conducting a comprehensive and continuous evaluation process for all variables related to science education and learning. The purpose is to develop this field and to apply the results of evaluation processes in developing science education, learning, and coping up with the curricula of scientific and technical developments (Anders et al., 2012; Atalmis, Avgin, Demir, \& Yildirim, 2016; Cornelius-White, 2007).

Trends in International Mathematics \& Science Study (TIMSS) are considered as one of the most important international studies which are most widespread on a global scale. It helps the participating countries to evaluate all elements of the educational process through a global vision. It assesses knowledge and students' skills around the world in the subjects of mathematics and science. It compares the students of each participating country with the rest of the countries. It helps the students to understand the world around them. It emphasizes the importance of developing higher-order thinking skills (Abd al-Salam \& Qarni, 2007; Mullis, Martin, Ruddock, \& Sulivan, 2008).

TIMSS is conducted every four years under the supervision of an international organization. The first international study was conducted after the association decided to evaluate students' performance in mathematics and science subjects in 1995. This study was applied to the third and fourth primary grades, to the first and second intermediate years, and the students of the second year of high school. 41 countries have participated in the session. In 1999, the second session of the TIMSS was held and applied to the fourth and second intermediate grades only with the participation of 38 countries (Becker, McElvany, \& Kortenbruck, 2010; Zaitoun, 2010). The TIMSS has been conducted regularly every four years i.e. 2003, 2007, 2011, 2015, and 2019. In the last session of 2019, it was distinguished by the fact that more than half of the participating countries undertook the study electronically. It launched the beginning of the electronic application of the study with the term e-TIMSS. The study has been applied traditionally through paper and pencil tests in other countries.

TIMSS questions include two dimensions. One is the content dimension and it refers to the nature of the topics that should be included in the content of science books. Biology topics make up 35\%, physics 25\%, chemistry $20 \%$ and earth sciences $20 \%$. The second is the cognitive dimension. It refers to the nature of thinking processes or mental skills that a student is supposed to have, as one of the outcomes of the science teaching and learning process. It includes two dimensions of knowledge and application at a rate of $35 \%$ each, and after inference by $30 \%$ (Baumert et al., 2010).

The student's performance in the TIMSS is classified into five levels (Mullis et al., 2008). These are advanced performance levels for a score range which is greater than 625, high-performance level for scores is between $550-$ 625 , medium performance level for scores is between 475-549, low-performance level for scores is between 400-474 and less than the low-performance level for scores is less than 400.

Several countries in the world make sure to participate in the international tests to study TIMSS. This concern got attention due to the importance of studying TIMSS in terms of measuring the progress in science and mathematics education in a country compared to other countries. It follows up the relative influences of teaching and learning in the fourth grade and compares them with those influences in the eighth grade. As TIMSS tests are conducted periodically every four years, in terms of a comparison between the teaching methods and educational aids. It identifies the best leading means to better education by comparing the results of the local tests with the results of other countries.

The results of the TIMSS also help to reform the curricula and provide an opportunity for comparison between the implemented curriculum, the intended curriculum, and the learned curriculum (Mullis et al., 2008). It helps to carry out the necessary educational reforms, which effectively contributes to the development of teaching and learning processes in line with modern trends in teaching and learning science and mathematics (Comas, 2014).

The Kingdom of Saudi Arabia first participated in TIMSS in 2003. Its objectives include: representing the Kingdom in international events, benefiting from the experiences of other countries participating in the study, investing \& developing the national human resources, raising the level of students' scientifically \& intellectually, and contributing to the development of the educational process in the Kingdom (Alhisan, 2015).

Due to the importance of the TIMSS, researchers began to investigate the reasons responsible for the low students' results in the TIMSS to suggest recommendations to improve educational systems. Alqifari (2020) study showed that a lack of adequate knowledge of teachers in TIMSS was responsible for low performance (Akiba, LeTendre, \& Scribner, 2007). It was also revealed that this was also caused by an over-dependence on traditional teaching methods. The study recommended developing a continuous evaluation system, using more advanced methods, and providing scholarships for teachers to pursue higher studies.

Peduk and Ates (2019) focused on comparing the content of the science curriculum developed for the intermediate school in 2018 with the requirements of the TIMSS and the high school admission test in Turkey. The study's results showed that the learning objectives in the fields of physics, life sciences, and earth sciences were identical in all intermediate school grades. The learning objectives in the field of chemistry were identical to the learning objectives of the seventh and eighth-grade textbooks (Claessens \& Engel, 2013). The results also showed 
that most of the secondary school entrance examination questions have corresponded to the cognitive levels in the TIMSS, which were mentioned within the cognitive dimension of the science test in the study.

Al-Ruwaili and Al-Anzi (2018) found that the rates of inclusion in general science and biology courses were low. The rates of inclusion of chemistry and physics were moderate. It also showed that the field of earth sciences was not achieved at all. The results of Yahya and Ayasrah (2018) study showed that the low level of performance of eighth-grade students in Jordan in the TIMSS in 2015 was due to the school administration, the reasons related to the school curriculum, the students and the reasons related to the teacher's performance (Cohen, McCabe, Michelli, \& Pickeral, 2009).

Boukahous (2017) also indicated that the general percentage of availability of the sub-requirements for the TIMSS was generally low in the content and cognitive processes dimensions. None of these percentages were consistent with the requirements of the TIMSS. Shehadeh and Al-Qarmaiti (2016) presented some proposals to develop students' performance in the TIMSS test. The most important of which was organizing courses that would contribute to raising the teachers' efficiency in mathematics and science in studying TIMSS to catch up with the developed countries in this field. Alhisan (2015) probed that the requirements of the TIMSS-2015 were in the three dimensions i.e. content, cognitive processes, and scientific investigation, which occurred in a reasonable percentage. Abu Aish (2015) investigated the factors related to the level of students' achievement in the Kingdom of Saudi Arabia in the TIMSS tests. The study included three main dimensions which are educational institutions, the teacher, and the family. It was recommended to prepare a strategy to raise the level of students' achievement in the Kingdom of Saudi Arabia in mathematics and science.

The results of the Al-Jabr (2014) study indicated some weaknesses that the rates of including requirements for the dimension of science content in the book were low, compared to the rates set by IEA in 2011. Al-Fares (2014)'s study found that the reasons for the low results of fourth-grade students in TIMSS tests from the viewpoint of the sample members were medium. The student and family field were scored in the first place, the teacher field occurred in second place, and the field of curriculum and its teaching scored at the last place (Dahl \& Lochner, $2012)$.

The Kingdom of Saudi Arabia should pay more attention to the great importance of developing the educational system to build a promising generation that may have diverse skills and cultures to be adapted for any scientific and technological developments (Al-Gharabli, 2015). Considering this interest, the Kingdom of Saudi Arabia in its vision 2030 has emphasized the importance of education and training and providing Saudi youth with the necessary knowledge and skills for future jobs (Vision, 2030). The Kingdom of Saudi Arabia has also sought to develop education by presenting the natural science and mathematics curriculum development project (Al-Shaya \& Abdel Hamid, 2011). Despite the efforts made by the Kingdom of Saudi Arabia to develop science curricula, the results are not satisfactory. The results are evident from The Saudi Ministry of Education (2020) and Education and Training Evaluation Authority (2019). The Kingdom's participation in science tests for the second intermediate grade in the TIMSS is summarized in Table 1.

Table-1. Results of the Kingdom's participation in the TIMSS sessions.

\begin{tabular}{|c|c|c|c|c|}
\hline Participation of the Kingdom of Saudi Arabia & 2003 & 2007 & 2011 & 2015 \\
\hline of points & 398 & 403 & 436 & 396 \\
\hline of participating countries & 47 & 50 & 42 & 39 \\
\hline Rank & 42 & 44 & 51 & 35 \\
\hline
\end{tabular}

The literature has indicated that the level of performance significantly declined in the 2015 session as the level of performance has declined to a low level in 2015 (Alanazi, 2017). Therefore, this present study aims at exploring the reasons behind this low score and presenting a proposed vision for developing the performance of second-grade intermediate students in science tests in TIMSS.

\section{Methods}

The study followed the descriptive and analytical approach as this approach is one of the most appropriate scientific research methodologies for the subject of the study. This approach is a set of research procedures carries out by the researcher to describe the studied phenomenon relying on collecting, classifying, processing, and analyzing the facts and data with sufficiently accurate analysis to extract its significance for the conclusions and generalizations of the results and policy implications. The descriptive analyses are also recommended by Attia (2009).

The study's population has consisted of all middle school science teachers, middle school science supervisors, and supervisors in the Kingdom of Saudi Arabia. The study sample consisted of 140 teachers and 60 school science supervisors, and supervisors in the following educational departments from Riyadh, Madinah, and Hafar Al-Batin. A questionnaire was used as a tool to collect information and to answer the questions of the current study. The questionnaire was prepared in the light of established literature about the prominent reasons responsible for a low level of participation in science's tests in TIMSS (Abu Aish, 2015; Al-Ruwaili \& Al-Anzi, 2018; Shehadeh \& AlQarmaiti, 2016). It consisted of three dimensions: the course content, the student, and the teacher, and the teaching performance. The questionnaire was applied electronically.

To verify the validity and relevance of the study to achieve its objectives, it was presented to a group of distinguished arbitrators from the faculty members of several Saudi universities to seek their views regarding the accuracy of the scientific and linguistic drafting of the questionnaire paragraphs. It was designed to determine the extent to which each paragraph belongs to the construct in which it was mentioned. To verify the validity of the internal consistency of the questionnaire, it was applied to an exploratory sample that consisted of 20 teachers and supervisors, who did not belong to the study sample. Then, we computed the correlation coefficient between the degree of each paragraph and the total degree of the construct to which it belonged. The results are as shown in Table 2. 
Table-2. Correlation coefficients between the degree of each paragraph and the total degree of the axis to which it belongs.

\begin{tabular}{c|c|c|c|c|c}
\hline \multicolumn{2}{c|}{ Academic content } & \multicolumn{2}{c|}{ Student } & \multicolumn{2}{c}{ Teacher \& teaching performance } \\
\hline Paragraph No. & $\begin{array}{c}\text { Correlation } \\
\text { coefficient }\end{array}$ & Paragraph No. & $\begin{array}{c}\text { Correlation } \\
\text { coefficient }\end{array}$ & Paragraph No. & $\begin{array}{c}\text { Correlation } \\
\text { coefficient }\end{array}$ \\
\hline 1 & $0.845^{* *}$ & 9 & $0.789^{* *}$ & 19 & $0.779^{* * *}$ \\
\hline 2 & $0.857^{* *}$ & 10 & $0.717^{* *}$ & 20 & $0.539^{*}$ \\
\hline 3 & $0.849^{* *}$ & 11 & $0.875^{* *}$ & 21 & $0.617^{* *}$ \\
\hline 4 & $0.756^{* *}$ & 12 & $0.598^{* *}$ & 22 & $0.582^{* *}$ \\
\hline 5 & $0.635^{* *}$ & 13 & $0.775^{* *}$ & 23 & $0.709^{* *}$ \\
\hline 6 & $0.848^{* *}$ & 14 & $0.893^{* *}$ & 24 & $0.682^{* *}$ \\
\hline 7 & $0.763^{* *}$ & 15 & $0.750^{* *}$ & 25 & $0.576^{* *}$ \\
\hline 8 & $0.730^{* *}$ & 16 & $0.906^{* *}$ & 26 & $0.715^{* *}$ \\
\hline & & 17 & $0.873^{* *}$ & 27 & $0.675^{* *}$ \\
\hline
\end{tabular}

Note: ** Significant correlation coefficient at a significance level of 0.01 .

It is evident from the results in Table 2 that the score of each paragraph correlates with a significant correlation coefficient with the total score of the axis/construct to which it belongs. The value of the correlation coefficients ranged between 0.539-0.857. The significance level of these coefficients was found at the level of 0.01, and the correlation coefficient between the degree of each axis and the total degree of the questionnaire was calculated. The results were as shown in Table 3.

Table-3. Correlation coefficients between the degree of each axis and the total degree of the questionnaire.

\begin{tabular}{c|c}
\hline Questionnaire axes & Correlation coefficient \\
\hline Academic content & $0.875^{* *}$ \\
\hline Student & $0.959^{* *}$ \\
\hline Teacher \& teaching performance & $0.892^{* *}$ \\
\hline
\end{tabular}

Note: ** Significant correlation coefficient at a significance level of 0.01

The results presented in Table 3 show that the degree of each axis is related to a significant correlation coefficient at a level of significance of 0.01 with the total score of the questionnaire. Together, these results confirm that the questionnaire has a high degree of validity of internal consistency. To verify the stability of the questionnaire, the Alpha Cronbach coefficient was calculated, and the results are shown in Table 4.

Table-4. The results of the reliability factor of the questionnaire.

\begin{tabular}{c|c}
\hline Stability coefficient & Correlation coefficient \\
\hline Academic content & 0.912 \\
\hline Student & 0.929 \\
\hline Teacher \& teaching performance & 0.845 \\
\hline The whole questionnaire & 0.955 \\
\hline
\end{tabular}

The results in Table 4 show that the stability of the coefficients for the questionnaire axes are ranging between 0.845-0.929. While the reliability coefficient for the entire questionnaire was 0.955. All these axes have high coefficients which confirm the stability of the questionnaire and the validity of its use to achieve the objectives of the study. After completing the procedures to verify the validity and reliability of the questionnaire, the questionnaire was drafted in its final form. It consisted of two parts. The first part contained the respondent's data and it included the name (optional), date of application, job title (teacher or supervisor), and teaching performance. The second part contained 28 paragraphs of the questionnaire. These were distributed on three main axes i.e. the academic content (eight paragraphs), the student (ten paragraphs), and the teacher \& the teaching performance (ten paragraphs).

Table 5. The quantitative estimate of the respondents' responses to the questionnaire.

\begin{tabular}{l|c|c|c|c|c}
\hline Degree of approval & Very high & High & Medium & Too low & Low \\
\hline Quantitative estimation & 5 & 4 & 3 & 2 & 1 \\
\hline Average relative weight & $4.21-5$ & $3.41-4.2$ & $2.61-3.4$ & $1.81-2.6$ & $1-1.8$ \\
\hline
\end{tabular}

As for the quantitative assessment of the responses of the sample members to the degree of agreement with the paragraphs of the questionnaire, it was executed according to a five-point Likert scale (1-5). The average relative weight of the responses was calculated by dividing the range by $(5-1=4)$. The class length was found by dividing the range (4) by the number of classes (5), meaning that the length of the class was 0.8 . Then add the class length to the smallest degree in the scale which was (1). It is possible to clarify the quantitative estimate of the responses of the sample members and the average relative weight of each response, as shown in Table 5.

\section{Data Analyses}

The Pearson correlation coefficient is utilized to calculate the validity of the internal consistency of the resolution, the Alpha-Cronbach coefficient is utilized to calculate the stability of the questionnaire, and the frequencies and percentages are utilized to calculate the responses of the sample members to the paragraphs of the questionnaire. We tested the question: "What are the reasons for the low performance of middle-grade and secondgrade students in science tests in TIMSS?" This question was answered by calculating the arithmetic means and standard deviations of the responses of the sample members. Then, the degree of the consent of the sample members to each of the instrument's paragraphs was determined separately and independently. The responses of the sample members, which were comprised of its first axis of educational content, are shown in Table 6. 
Table-6. Responses of the sample members on the study content axis.

\begin{tabular}{|c|c|c|c|c|}
\hline No. & Educational content & $\begin{array}{l}\text { Arithmetic } \\
\text { mean }\end{array}$ & $\begin{array}{l}\text { standard } \\
\text { deviation }\end{array}$ & Approval degree \\
\hline 1 & The course content does not match the teaching time. & 4.4 & 0.75 & Very high \\
\hline 2 & $\begin{array}{l}\text { The academic content is not concerned with the } \\
\text { interconnectedness between } \\
\text { applications, and life situations. }\end{array}$ & 3.34 & 0.95 & Medium \\
\hline 3 & $\begin{array}{l}\text { The scarcity of interest in scientific inquiry activities in } \\
\text { academic content. }\end{array}$ & 4.07 & 0.57 & High \\
\hline 4 & $\begin{array}{l}\text { Lack of interest in the academic content of providing } \\
\text { students with scientific culture. }\end{array}$ & 4.27 & 0.76 & Very high \\
\hline 5 & $\begin{array}{l}\text { The lack of interest in the study content in developing } \\
\text { scientific inference skills. }\end{array}$ & 4.63 & 0.57 & Very high \\
\hline 6 & $\begin{array}{l}\text { Lack of questions and activities aimed at developing } \\
\text { higher-order thinking skills. }\end{array}$ & 4.53 & 0.63 & Very high \\
\hline 7 & The course content is more theoretical than practical. & 4.13 & 0.76 & High \\
\hline 8 & $\begin{array}{l}\text { The scarcity of examples and activities related to } \\
\text { international exams in the science subject in the } \\
\text { academic content. }\end{array}$ & 4.67 & 0.47 & Very high \\
\hline \multicolumn{2}{|c|}{ Total } & 4.25 & 0.80 & Very high \\
\hline
\end{tabular}

It is clear from the responses in Table 6 that the degree of approval of the sample members to the related reasons to the course content was very high. The approval of five reasons comes up with a very high level of acceptance. The response in two paragraphs had a high degree of approval, and one paragraph had a medium degree of approval. These responses indicate that the course content is inconsistent with the nature of the science test in TIMSS, in terms of examples and skills related to the cognitive dimension and the content dimension. It is combined with the need for further enrichment of content activities and examples related to questions like those included in the science test in TIMSS. The lack of examples, which work to link the subject of science with its life and practical applications, and the focus on theoretical aspects are more than the practical. In addition to the density of the course content, the disproportion between the amount of this content and the academic time allocated to teaching is consistent with the previous studies. This showed that the ratios of inclusion of the two dimensions of content and cognitive processes in the second intermediate grade textbook have fallen below the level of the requirements of the TIMSS test (Al-Jabr, 2014; Al-Ruwaili \& Al-Anzi, 2018). It was also mentioned in another study that the process of developing science and mathematics curricula was not considering the requirements of international competitions (Shehadeh \& Al-Qarmaiti, 2016).

\begin{tabular}{|c|c|c|c|c|}
\hline No. & The student & Arithmetic mean & Standard deviation & Approval degree \\
\hline 1 & $\begin{array}{l}\text { Students find it difficult to acquire abstract } \\
\text { scientific concepts. }\end{array}$ & 4.14 & 1.16 & High \\
\hline 2 & $\begin{array}{l}\text { Students' lack of awareness of the } \\
\text { importance of taking the TIMSS test } \\
\text { seriously. }\end{array}$ & 4.51 & 0.74 & Very high \\
\hline 3 & $\begin{array}{l}\text { The density of the number of students in } \\
\text { the classroom. }\end{array}$ & 4.43 & 0.84 & Very high \\
\hline 4 & $\begin{array}{l}\text { Low level of basic science competencies } \\
\text { among students. }\end{array}$ & 4.33 & 0.91 & Very high \\
\hline 5 & $\begin{array}{l}\text { Lack of training in questions that require } \\
\text { higher thinking skills. }\end{array}$ & 3.97 & 0.98 & High \\
\hline 6 & $\begin{array}{llll}\begin{array}{l}\text { Weak scientific reasoning skills of } \\
\text { students. }\end{array} & & \\
\end{array}$ & 4.24 & 0.73 & Very high \\
\hline 7 & Poor application skills of students. & 4.47 & 0.68 & Very high \\
\hline 8 & Poor level of knowledge skills of students. & 3.89 & 0.48 & High \\
\hline 9 & $\begin{array}{l}\text { Students are not adequately prepared for } \\
\text { the TIMSS test. }\end{array}$ & 4.66 & 0.93 & Very high \\
\hline 10 & $\begin{array}{l}\text { The presence of negative attitudes among } \\
\text { students towards science. }\end{array}$ & 4.31 & 0.71 & Very high \\
\hline Total & & 4.29 & 0.86 & Very high \\
\hline
\end{tabular}

The responses of the sample members, which are regarded as the reasons related to the student, are shown in Table 7. The responses of the sample members to the reasons related to the student come up with a very high degree of agreement. The responses of seven reasons have a very high degree of acceptance and three reasons have a high degree. These results indicate the need to review many aspects related to the educational process in general, and the aspects related to science education. The number of students in the classroom must be reduced which would facilitate the teacher's work. It may allow involving the largest possible number of students in educationallearning activities. There is a need to educate students because the results of participation in international competitions are a matter of great importance to the education process in the Kingdom.

A pilot test for the TIMSS test must be held before the official date for the international test. This test is limited to some schools, and it is not generalized to all schools and educational departments. Schools or national tests do not include questions that are in the TIMSS questions. In addition to the above, there is a dire need to pay attention to the skillful and emotional aspects of teaching and learning sciences. It must not limit attention to the cognitive aspect as well. The results of this axis agree with some previous studies which are dealt with studentrelated causes as one of the reasons for low performance in TIMSS (Al-Fares, 2014; Atalmis et al., 2016; Yahya \& Ayasrah, 2018). 
Table-8. Responses of the sample members on the axis teacher and teaching performance.

\begin{tabular}{|c|c|c|c|c|}
\hline No. & The teacher \& teaching performance & Arithmetic mean & Standard deviation & Approval degree \\
\hline 1 & $\begin{array}{l}\text { Teachers deemed unnecessary participation in } \\
\text { the TIMSS study. }\end{array}$ & 4.47 & 0.70 & Very high \\
\hline 2 & $\begin{array}{l}\text { Teachers are not informed of TIMSS study } \\
\text { questions. }\end{array}$ & 4.57 & 0.73 & Very high \\
\hline 3 & $\begin{array}{l}\text { Training courses are not organized to raise } \\
\text { awareness of international tests in science. }\end{array}$ & 4.71 & 0.46 & Very high \\
\hline 4 & Committing to traditional methods of teaching. & 4.09 & 0.63 & High \\
\hline 5 & The textbook is the only source of information. & 4.13 & 0.74 & High \\
\hline 6 & $\begin{array}{l}\text { The scarcity of using modern technologies in } \\
\text { science education. }\end{array}$ & 3.84 & 0.94 & High \\
\hline 7 & $\begin{array}{l}\text { Difficulty in applying alternative evaluation } \\
\text { methods. }\end{array}$ & 4.27 & 0.70 & Very high \\
\hline 8 & $\begin{array}{l}\text { Lack of interest in conducting practical } \\
\text { experiments. }\end{array}$ & 3.89 & 0.86 & High \\
\hline 9 & $\begin{array}{l}\text { Lack of adequate support for teachers with } \\
\text { excellent teaching performance. }\end{array}$ & 4.39 & 0.84 & Very high \\
\hline 10 & $\begin{array}{l}\text { Too much administrative work was assigned to } \\
\text { the teacher. }\end{array}$ & 4.37 & 0.68 & Very high \\
\hline Total & & 4.27 & 0.87 & Very high \\
\hline
\end{tabular}

Table-9. A proposed vision for developing the performance of second-grade intermediate students in science tests in TIMSS.

\section{\begin{tabular}{l|l}
\hline Course content & Student \\
\hline
\end{tabular}}

- Including the content of $\bullet$ Reducing the number of students the four dimensions of in school classrooms to facilitate science i.e. chemistry, their participation in scientific physics, biology, and earth and investigative activities. sciences in the proportions required by the study of TIMSS.

- Including science content in samples of previous TIMSS test questions to train students on.

- Interest in activities and questions that stimulate higher thinking skills.

- Emphasizing the content on the importance of the participation of middlegrade students in TIMSS study.

- Providing enrichment activities to enhance the scientific culture of students by referring to the various sources of knowledge on the internet.

- Considering the proportionality between the theoretical and the practical side.

- Including various investigative activities that include developing skills related to the knowledge dimension of the TIMSS test in terms of knowledge, application, and inference skills.

- Enriching the content with information about developed countries in TIMSS tests for previous years.

- Linking established topics and life situations.

- Training students in investigative skills and acting out the role of scholars.

- Assigning students to submit research papers that include introducing TIMSS tests, their importance, and presenting the experiences of developed countries.

- Disseminating TIMSS test experience for all intermediate second-grade students in the Kingdom.

- Apply various strategies to develop students' knowledge dimension skills including knowledge, application, and inference skills.

\section{Teacher \& teaching performance}

- Conducting training courses for science teachers to achieve the following objectives: introducing the importance of science in the progress of countries, introducing the study of TIMSS and its role in developing science education and learning, reviewing the experiences of developed countries in TIMSS tests and the reasons for their progress, reviewing the results of the Kingdom of Saudi Arabia in previous tests and the reasons that led to their delay by reviewing the results of previous research and studies in this field, and introducing them to the most important recommendations made by previous research and studies to develop the Kingdom's progress in TIMSS tests.

Training teachers in formulating questions like the questions included in TIMSS tests and training them in how to train students to prepare for TIMSS tests.
Include a teacher's guide for teaching science on the sample questions contained in TIMSS studies with their model answers.

- Providing modern technologies, training teachers on their use, and how to employ them in science teaching to attract students' interest in science.

- Developing science laboratories, providing equipment, and encouraging teachers to use $\&$ activate them in training students on the practical side

- Holding training courses to activate virtual laboratories to implement investigative science activities.

- Holding training courses to develop the performance of science teachers to use modern strategies effectively in science teaching.

- Holding training courses to develop the performance of science teachers to use alternative evaluation methods to evaluate students' performance instead of limiting themselves to traditional evaluation methods.

- Reducing the administrative burdens assigned to science teachers to follow up on students' performance in curricular \& extracurricular activities and to develop their performance by finding time to attend development courses. 
The responses of the sample members on the second axis, which are regarded as the related reasons to the teacher \& the teaching performance, are shown in Table 8. The responses of the sample members of the related reasons to the teacher came with a very high degree of agreement. The responses of six reasons on this axis have a very high degree and four have a high degree. These results indicate the need to pay attention to continuous training for the teacher as one of the methods of developing the performance of the teachers. It is important to conduct the training courses related to international tests in the subject of science, to increase their knowledge of these tests, and to develop their awareness of the importance of effective participation. These results are consistent with previous studies that recommended the need to develop curricula and reduce the burden of administrative work on teacher's (Alqifari, 2020; Yahya \& Ayasrah, 2018). It is evidenced by previous studies that teachers' quorum from the lessons and unawareness of TIMSS and science tests are the other crucial reasons (Al-Fares, 2014; Shehadeh \& Al-Qarmaiti, 2016).

We tested the second question: "What is the proposed vision for developing the performance of second-grade intermediate students in science tests in TIMSS?". Considering the above results of the second-grade students' participation in science's tests in TIMSS, we mention the reasons for the current study's results related to each of the course content, the student, and the teacher \& the teaching performance. We present a proposed conception aimed at developing the performance of intermediate second-grade students in science tests in TIMSS, which is presented in Table 9.

\section{Conclusion and Recommendations}

Considering the results of the current study, it is recommended to benefit from the proposed scenario to improve the performance of second-grade intermediate students in science's tests in the study of TIMSS. It is suggested to issue an educational scientific journal, devoted entirely to introduce international studies in the subject of science, which should publish the results of research from the participating countries of TIMSS and the participation of the Kingdom of Saudi Arabia. This journal should include examples of the questions containing the methods that the teacher can follow to improve students' performance in international studies. It is proposed that the level of pilot tests that are held be raised to prepare students to participate in TIMSS and to circulate these tests to all schools in the Kingdom. It is also advised to conduct further studies aimed at comparing some of the variables related to science education and learning in countries with advanced performance and the Kingdom of Saudi Arabia so, we may identify the systems of preparing science teachers, developing teachers' professional performance, academic content, teaching methods, and evaluation methods. These contents may be extracted from different educational systems in the world.

\section{References}

Abd al-Salam, A. A., \& Qarni, Z. A. S. (2007). A proposed model for developing the science curriculum at the primary education stage in light of the requirements of the TIMSS project. Paper presented at the The eleventh conference, Scientific Education.

Abu Aish, B. R. (2015). A proposed scenario to develop the performance level of Saudi Arabia's students in science and mathematics in light of their participation in international studies for them. Journal of the College of Education, 34(162), 161-186.

Akiba, M., LeTendre, G. K., \& Scribner, J. P. (2007). Teacher quality, opportunity gap, and national achievement in 46 countries. Educational Researcher, 36(7), 369-387.

Al-Fares, S. A. (2014). Reasons for the low fourth grade students in TIMSS tests for the science subject from the viewpoint of their teachers and science directors in the State of Kuwait. A magister message that is not published. Amman: University of the Middle East, College of Educational Sciences.

Al-Gharabli, M. A. A. (2015). The impact of a training program for mathematics teachers based on the trends of the international study in mathematics and science timss on their students' ability to mathematical knowledge, application and mathematical reasoning. Dirasat Journal: Educational Sciences, 42(3), 1115-1135.

Al-Jabr, M. (2014). The level of inclusion in the second intermediate grade science textbook in the Kingdom of Saudi Arabia for the requirements of the International Trends for the study of science and mathematics (TIMES) project. Journal of the College of Education, 25(99), 271-307.

Al-Ruwaili, F. F., \& Al-Anzi, F. M. (2018). Analyzing the content of the science course for the second intermediate grade in the Kingdom of Saudi Arabia in light of the requirements for the study of international trends in mathematics and science TIMSS 2015. Al-Hikmah Journal for Educational and Psychological Studies 15(1), 30-38.

Al-Shaya, F. S., \& Abdel Hamid, A. N. M. (2011). Project for developing mathematics and natural sciences curricula in the Kingdom of Saudi Arabia (hopes and challenges). The fifteenth scientific conference: Scientific education, a new thought for a new reality (pp. 6-7). Cairo: Egyptian Society for Scientific Education. September.

Alanazi, F. H. (2017). Effectiveness of the proposed training formative assessment programme and its impact on teaching style improvements of saudi science teachers in Saudi Arabia. Journal of Turkish Science Education, 14(1), 35-56.

Alhisan, A. M. (2015). The extent to which the requirements of the International trends for the study of mathematics and science project (TIMSS-2015) are fulfilled in the first to fourth elementary grades science textbooks in the Kingdom of Saudi Arabia: An analytical study. Zarqa Journal of Humanitarian Studies and Research, 15(1), 111-132.

Alqifari, A. (2020). The extent of saudi teachers' knowledge of TIMSS' policies and assessment practices. Journal of Contemporary Scientific Research, 4(2), 8-21.

Anders, Y., Rossbach, H.-G., Weinert, S., Ebert, S., Kuger, S., Lehrl, S., \& Von Maurice, J. (2012). Home and preschool learning environments and their relations to the development of early numeracy skills. Early Childhood Research Quarterly, 27(2), 231-244. Available at: https://doi.org/10.1016/j.ecresq.2011.08.003.

Atalmis, E. H., Avgin, S. S., Demir, P., \& Yildirim, B. (2016). Examination of science achievement in the 8th grade level in Turkey in terms of national and international exams depending upon various variables. Journal of Education and Practice, 7(10), $152-162$.

Attia, M. A. (2009). Scientific research in education: Its methods, tools and statistical means. Amman: House of Approaches for Publishing and Distribution.

Baumert, J., Kunter, M., Blum, W., Brunner, M., Voss, T., Jordan, A., . . T Tsai, Y.-M. (2010). Teachers' mathematical knowledge, cognitive activation in the classroom, and student progress. American Educational Research Journal, 47(1), 133-180. Available at: https://doi.org/10.3102/0002831209345157.

Becker, M., McElvany, N., \& Kortenbruck, M. (2010). Intrinsic and extrinsic reading motivation as predictors of reading literacy: A longitudinal study. Journal of Educational Psychology, 102(4), 773-785. Available at: https://doi.org/10.1037/a0020084.

Boukahous, K. A. (2017). The extent to which the content of science books for grades five to eight basic in the Kingdom of Bahrain includes the requirements of international trends in mathematics and science. Journal of Educational and Psychological Sciences, 18(3), 11-44.

Claessens, A., \& Engel, M. (2013). How important is where you start? Early mathematics knowledge and later school success. Teachers College Record, 115(6), $111-129$.

Cohen, J., McCabe, L., Michelli, N. M., \& Pickeral, T. (2009). School climate: Research, policy, practice, and teacher education. Teachers College Record, $111(1), 180-213$. 
Comas, W. (2014). The language of science education: An expanded glossary of key terms and concepts in science teaching and learning. Netherlands: Sense Publishers.

Cornelius-White, J. (2007). Learner-centered teacher-student relationships are effective: A meta-analysis. Review of Educational Research, 77(1), 113-143. Available at: https://doi.org/10.3102/003465430298563.

Dahl, G. B., \& Lochner, L. (2012). The impact of family income on child achievement: Evidence from the earned income tax credit. American Economic Review, 102(5), 1927-1956.

Education and Training Evaluation Authority. (2019). The guide for international tests TIMSS 2019. Riyadh: The National Center for Measurement, Education and Training Evaluation Authority.

Mullis, V., Martin, O., Ruddock, J., \& Sulivan, O. (2008). TIMSS 2007 assessment frame works from IEA TIMSS E PIRLS. Boston: International Study center, Lynch School of Education.

Peduk, B., \& Ates, O. (2019). Analysis of the science course curriculum objectives and high school entrance examination questions according to timss framework. International Journal of Educational Methodology, 5(3), 433-449.

Shehadeh, F. I., \& Al-Qarmaiti, A. (2016). The level of achievement of students in the Kingdom of Saudi Arabia in mathematics and science according to the results of international studies (TIMSS) compared to other countries from the viewpoint of teachers and supervisors: causes, solutions, treatment and methods of development. Journal of the College of Education, 169(1), 327-372.

The Saudi Ministry of Education. (2020). Riyadh: The Saudi ministry of education. Retrieved from: www.moe.gov.sa. [Accessed 16th March $2020]$.

Yahya, S., \& Ayasrah, M. (2018). Causes of 8th grade students' low achievement in TIMSS study-2015 from science teachers and educational supervisors. Review of European Studies, 11(1), 124-139.

Zaitoun, A. M. (2010). Contemporary global trends in science curricula and teaching them. Amman: Dar Al Shorouk. 